\title{
Looking for 'fresh' food: diet and lone parents
}

\author{
BY ELIZABETH DOWLER AND CLAIRE CALVERT \\ Human Nutrition Unit, Department of Public Health and Policy, London School of Hygiene and \\ Tropical Medicine, University of London, 2 Taviton St, London WC1H OBT
}

'Health and disease cannot be defined merely in terms of anatomical, physiological or mental attributes. Their real measure is the ability of the individual to function in a manner acceptable to himself and to the group of which he is a part.' (Dubos, 1984)

'Food choice' is a potential locus of debate between social scientists concerned with observing and interpreting people's food behaviour (purchase, preparation, allocation and consumption) in terms of beliefs and meanings, and policy makers and health workers for whom 'informed consumer choice' underpins contemporary policy in nutrition and preventive health. Whether 'food choice' is always and exclusively an aspect of 'behaviour' is a moot point; nevertheless those who promote 'healthy eating', along with smoking less and taking more exercise, as antidotes to excess morbidity and premature mortality, are arguably operating on the premise that those experiencing these conditions are 'behaving badly', or at least, inappropriately. 'Food behaviour' can encompass not only what and why particular food commodities are bought and how they are prepared, but also what kind of shops people choose to patronize, how they allocate money from a limited budget to food, and what kinds of priority poor people place on different kinds of food.

Some preventative and public health interventions in food for low-income groups have been implicitly based on assumptions that poor people inevitably look primarily for food that is cheap, and also that poor people do not know what foods are best for health. By contrast, the literature often shows that poor people's food aspirations are no different from the general population's, nor is their general knowledge of the role of food in maintaining good health, and that poor households' familiarity with current specific 'healthy eating guidelines' is also no worse than that of the general population (Dobson et al. 1994; Williams \& Dowler, 1994). Research in the nutrition field has tended to use occupational social class rather than geographical location, deprivation indices or income to identify poor households and, therefore, is not measuring differences in food choice attributable to income or deprivation (Dowler \& Rushton, 1994).

\section{SURVEY OF LONE-PARENT HOUSEHOLDS' NUTRITION AND DIET}

\section{Background and methods}

The recent survey of diets and nutritional conditions in lone-parent households in London (Dowler \& Calvert, 1995) produced findings pertinent to this debate. We were particularly interested in documenting the nutritional consequences of strategies lone parents adopt where money is tight and food choice constrained. Lone parenthood (defined by the state as families with a mother or father living without a spouse and not cohabiting, with her or his never-married dependent child(ren), aged under 16 years, or 16-19 years and in full-time education (Department of Health and Social Security, 1974)) 
is not a pathological or unusual state, but one common to many parents and children in Britain at some stage. We chose to look at these households partly because not much was known about their food and diet, and partly to investigate nutritional conditions of low-income households. Many lone parents, whether single, separated or divorced, live on low incomes, either because they work part-time or in low-waged jobs, especially if they are female, or because they have no job and rely primarily on the state for the means-tested benefit of Income Support: of the 1.3 million lone parents in the UK in 1993, 1013000 were claiming Income Support (Department of Social Security, 1994). Few lone parents receive significant contributions to their household income from the absent parent (Burghes, 1993).

A random sample of lone-parent households in Greater London was contacted via the Department of Social Security in 1992-3. Details of the survey methodologies, sampling response rates and nutrient intakes have been reported elsewhere (Dowler \& Calvert, 1995). Briefly, nutrition data were obtained from individual $3 \mathrm{~d}$ weighed food intake records for parent and child(ren), and from a food-frequency questionnaire (FFQ) addressed to parents and child(ren). Taped, semi-structured interviews examined food management, beliefs and household budgeting in relation to food and health. These interviews were not fully transcribed but post-coded; much of the narrative material was thereby captured as quantitative responses for the first analysis.

Indicators of socio-economic status were derived from the data: income per head, and adjusted for household size and composition (Central Statistical Office, 1994), occupational social class, educational qualifications, receipt of means-tested state benefits (Income Support), unemployment, housing tenure. In addition, a number of composite indices of deprivation were created (Townsend et al. 1987); the material deprivation index is reported here. Three sets of indicators of dietary and nutritional adequacy were derived. First, nutrient intakes in relation to the current Department of Health (1991) dietary reference values (DRV) which were chosen for each individual according to weight, age and activity level. The lower a group's mean nutrient intake was as a percentage of the reference intake, the less likely all members of the group were to be eating enough of that nutrient to avoid ill-health. The probability of deficiency increased as the percentage of the reference value (DRV) achieved decreased. In particular, individuals whose intakes of vitamins or minerals were very low, below the lower reference nutrient intake (LRNI; Department of Health, 1991), were at very high risk of inadequate nutrient intakes.

Second, variety-frequency scores (VFS) based on ecological ideas of diversity and abundance (Myatt \& Dowler, 1995) were calculated from the FFQ to estimate food-usage variety. The FFQ was based on that used by Wheeler et al. (1989) and the Caerphilly study (Yarnell et al. 1983) with some modification following pilot studies. The list comprised 164 separate food items, including a number of so-called 'ethnic minority' foods, with, for instance, seventeen and forty-two entries under fruits and vegetables respectively. For each food respondents were asked 'how often do you/your children eat ' $x$ '?' with five possible responses (most days, once or twice per week, two or three times per month, occasionally, never). A set of close-to-linear frequency weightings were applied to these responses to assign an approximation of how many days per month each food item would be consumed. These weightings were summed for each household for parent and children separately to produce a simple VFS for all foods (referred to here as 'total variety') and for food-usage variety within food types (fruit, vegetables, cereals, 
meat, fish). The assumption was that the lower an individual's or group's VFS the less likely they were to be achieving sufficient variety for health. The distributions of the VFS for total variety, vegetables, fruit, fish, meat and cereals were examined and minor departures from normality were corrected by $\log$ transformation. The VFS for fruit and vegetables were correlated with intakes of vitamin $C$, folate and NSP in the same households. Correlations were significant at $P<0 \cdot 01$, but were weak $(0 \cdot 3-0 \cdot 4)$.

Third, healthy dietary patterns were derived from indicators of consumption of foods particularly recommended as healthy. Foods listed in the FFQ were ranked crudely in terms of whether or not current healthy eating guidelines recommend eating more of it, less of it, or are neutral about it (e.g. Department of Health, 1994). This ranking was combined with the VFS to produce a healthy diet score for each parent and for their child(ren). So, 'recommended' foods eaten more often, contributed most to the healthy diet index; 'go easy' foods eaten more often, reduced the healthy diet score. Second, the responses for fruit and vegetables in the FFQ were used to calculate the probability that parents and children were eating at least five different fruits or vegetables per d (Williams, 1994). The weighted responses were summed and grouped as below $2 \cdot 5,2 \cdot 5-5$ and 5 and over, to produce a fruit-vegetable indicator for parents and children. The higher the healthy diet score, a fruit and vegetable score of 5 and over, and the lower the percentage energy in the diet from total fat and saturated fat, measured in the dietary survey, the healthier the diet.

\section{Survey findings: sample characteristics}

The socio-demographic characteristics of the 200 lone parents with whom contact was made are shown in Table 1 , and are very similar to two national surveys of lone-parent households, with the exception of ethnicity; there were more black African, British or Caribbean households in the London sample. Ethnicity apart, therefore, the quantitative findings can be generalized to the British lone-parent population. Table 2 shows the survey response rates. The sampling target was to obtain usable dietary records on 160 households (minimum 120); from previous experience of surveying lone-parent households (Bradshaw \& Millar, 1991) and the pilot survey a non-response rate of $55 \%$ was anticipated. The total sample was 350; contact was made with 200, 189 parents completed the full interviews and FFQ and 131 households completed usable dietary records; acceptable response rates. Two-thirds of the sample were households of lone parent and dependent children only; the remainder had older, non-dependent children or other adults living in complex households. None of these household composition factors showed any relationship to the nutrition outcomes. Mean total weekly income in the sample (unadjusted for household size and composition) was $£ 129$, for those claiming Income Support it was $£ 87$, and for those not, $£ 226$. There were no differences in household income by ethnic group.

\section{Survey findings: nutrients and dietary variety}

Whichever indicators of socio-economic status were used, nutrient intakes of the poorest lone parents were always lower, and their dietary patterns less healthy, than those who were not poor (Fig. 1; Calvert et al. 1994). Those who ate diets typical of black British or Afro-Caribbean households had higher micronutrient intakes, better VFS and healthy 
Table 1. Characteristics of lone parents (\% total) in nutrition and national surveys (From Dowler \& Calvert, 1995)

\begin{tabular}{|c|c|c|c|}
\hline Survey ... & $\begin{array}{l}\text { Nutrition survey } \\
1992-3 \text { n } 200\end{array}$ & $\begin{array}{l}\text { DSS } 1989 \text { (Bradshaw } \\
\text { \& Millar, 1991) n } 1428\end{array}$ & $\begin{array}{l}\text { DSS } 1991 \text { (McKay \& } \\
\text { Marsh, 1994) } n 2200\end{array}$ \\
\hline \multicolumn{4}{|l|}{ Marital status } \\
\hline Divorced & 36 & 44 & 36 \\
\hline Separated & 19 & 20 & 17 \\
\hline Single* & 42 & 37 & 46 \\
\hline Other & 4 & & \\
\hline \multicolumn{4}{|l|}{ Gender } \\
\hline Female & 95 & 95 & 94 \\
\hline Male & 5 & 5 & 6 \\
\hline \multicolumn{4}{|l|}{ Nos. of dependent children } \\
\hline 1 & 39 & 53 & 45 \\
\hline 2 & 32 & 32 & 35 \\
\hline 3 & 20 & 11 & 15 \\
\hline 4 plus & 8 & 4 & 5 \\
\hline \multicolumn{4}{|l|}{ Age (years) } \\
\hline Under 25 & 12 & 24 & 17 \\
\hline $25-29$ & 17 & 21 & 22 \\
\hline $30-34$ & 19 & 20 & 21 \\
\hline $35-49$ & 46 & 33 & 35 \\
\hline$>50$ & 6 & 3 & 4 \\
\hline \multicolumn{4}{|l|}{ Average age (years) } \\
\hline Divorced & 40 & 36 & 36 \\
\hline Separated & 39 & 33 & 34 \\
\hline Single & 30 & 26 & 29 \\
\hline All subjects & 36 & 32 & 33 \\
\hline \multicolumn{4}{|l|}{ Age (years) of youngest child } \\
\hline $0-4$ & 42 & 46 & na \\
\hline $5-9$ & 22 & 26 & na \\
\hline $10-15$ & 27 & 21 & na \\
\hline Over 16 & 8 & 6 & na \\
\hline \multicolumn{4}{|l|}{ Ethnic group (self-defined) } \\
\hline White European & 60 & 89 & na \\
\hline \multicolumn{4}{|l|}{ Caribbean origin or black } \\
\hline British & 25 & 4 & na \\
\hline African origin & 10 & 1 & na \\
\hline South-east Asian origin & 2 & 1 & na \\
\hline Other or refusal & 4 & 5 & na \\
\hline \multicolumn{4}{|l|}{ Tenure } \\
\hline Owned outright & 4 & 4 & 3 \\
\hline Owner with mortgage & 13 & 24 & 25 \\
\hline Local authority rented & 61 & 57 & 53 \\
\hline Housing Association rented & 7 & 6 & 5 \\
\hline Private rented & 6 & 6 & 9 \\
\hline Living with family or other & 10 & 3 & 5 \\
\hline \multicolumn{4}{|l|}{ Employment } \\
\hline Full time $(>30 \mathrm{~h} /$ week $)$ & 20 & 19 & na \\
\hline Part time (up to $30 \mathrm{~h} /$ week) & 12 & 21 & na \\
\hline Not employed & 68 & 60 & na \\
\hline Irregular employment & 2 & na & na \\
\hline
\end{tabular}


Table I continued

\begin{tabular}{|c|c|c|c|}
\hline Survey . .. & $\begin{array}{l}\text { Nutrition survey } \\
1992-3 \text { n } 200\end{array}$ & $\begin{array}{l}\text { DSS } 1989 \text { (Bradshaw } \\
\& \text { Millar, 1991) } n 1428\end{array}$ & $\begin{array}{l}\text { DSS } 1991 \text { (McKay \& } \\
\text { Marsh, 1994) n } 2200\end{array}$ \\
\hline \multicolumn{4}{|l|}{ Social security benefits } \\
\hline Income Support & 70 & 70 & 68 \\
\hline One Parent Benefit & 86 & 69 & 61 \\
\hline Family Credit & 5 & 7 & 10 \\
\hline \multicolumn{4}{|l|}{ Education qualifications } \\
\hline None & 44 & na & na \\
\hline GCE O level and/or CSE & 26 & na & na \\
\hline GCE A level & 6 & na & na \\
\hline $\begin{array}{l}\text { Degree, technical, } \\
\text { professional or vocational }\end{array}$ & 20 & na & na \\
\hline
\end{tabular}

DSS, Department of Social Security; GCE, General Certificate of Education; CSE, Certificate of Secondary Education; na, not available.

* In the nutrition survey, those who classified themselves as 'single' had never been married, but may have cohabited at some time. Those who separated from cohabitation are also included under 'single' in the DSS 1991 survey. Respondents in the nutrition survey, the 'parent with care', were not always the biological parent of the dependent child(ren): sometimes they were grandparents or siblings.

Table 2. London Lone-Parent Household Survey. Sampling response rates

\begin{tabular}{|c|c|c|c|c|c|c|}
\hline & $\begin{array}{l}\text { Sample } \\
\text { size }\end{array}$ & $\begin{array}{l}\text { Withdrew } \\
\text { at DSS } \\
\text { stage }(\%)\end{array}$ & $\begin{array}{c}\text { Moved or } \\
\text { ineligible }(\%)\end{array}$ & $\begin{array}{c}\text { No } \\
\text { contact }(\%)\end{array}$ & $\begin{array}{l}\text { Refused } \\
(\%)\end{array}$ & $\begin{array}{c}\text { Took } \\
\text { part }(\%)\end{array}$ \\
\hline \multicolumn{7}{|l|}{$\begin{array}{l}\text { Survey round } \\
1-4 \text { (Child Benefit }\end{array}$} \\
\hline sample) & 200 & $7 \cdot 5$ & 9 & 10 & 11 & $62 \cdot 5$ \\
\hline 5-7 (IS sample) & 150 & 10 & 10 & 14 & 16 & 50 \\
\hline 1-7 (total sample) & 350 & 8.6 & 9 & $11 \cdot 7$ & $13 \cdot 1$ & $57 \cdot 1$ \\
\hline Addresses received & 320 & - & $10 \cdot 3$ & $12 \cdot 8$ & $14 \cdot 4$ & $62 \cdot 5$ \\
\hline $\begin{array}{l}\text { Those eligible of } \\
\text { addresses received }\end{array}$ & 287 & - & - & $14 \cdot 3$ & $16 \cdot 0$ & $69 \cdot 7$ \\
\hline $\begin{array}{l}\text { Those eligible of } \\
\text { total sample }\end{array}$ & 317 & $9 \cdot 5$ & - & $12 \cdot 9$ & $14 \cdot 5$ & $63 \cdot 1$ \\
\hline $\begin{array}{l}\text { Those eligible who } \\
\text { completed interview }\end{array}$ & 189 & - & - & - & - & $59 \cdot 6$ \\
\hline $\begin{array}{l}\text { Those eligible with } \\
\text { dietary record } \\
\text { (households) }\end{array}$ & 131 & - & - & - & - & $41 \cdot 3$ \\
\hline
\end{tabular}

DSS, Department of Social Security; IS, Income Support.

dietary patterns than those eating diets typical of white households (Dowler \& Calvert, 1995).

Table 3 shows factors associated with high VFS for total variety in parents' diets, and Table 4 factors associated with high VFS for fruit and vegetable variety combined in children's diets. Similar patterns were obtained for other VFS and for healthy dietary patterns. There was marked differentiation of dietary variety as measured by VFS, and healthier dietary patterns, by indicators of shopping, cooking and eating practices, and of people's stated aspirations towards food. During the long taped interview, parents were 


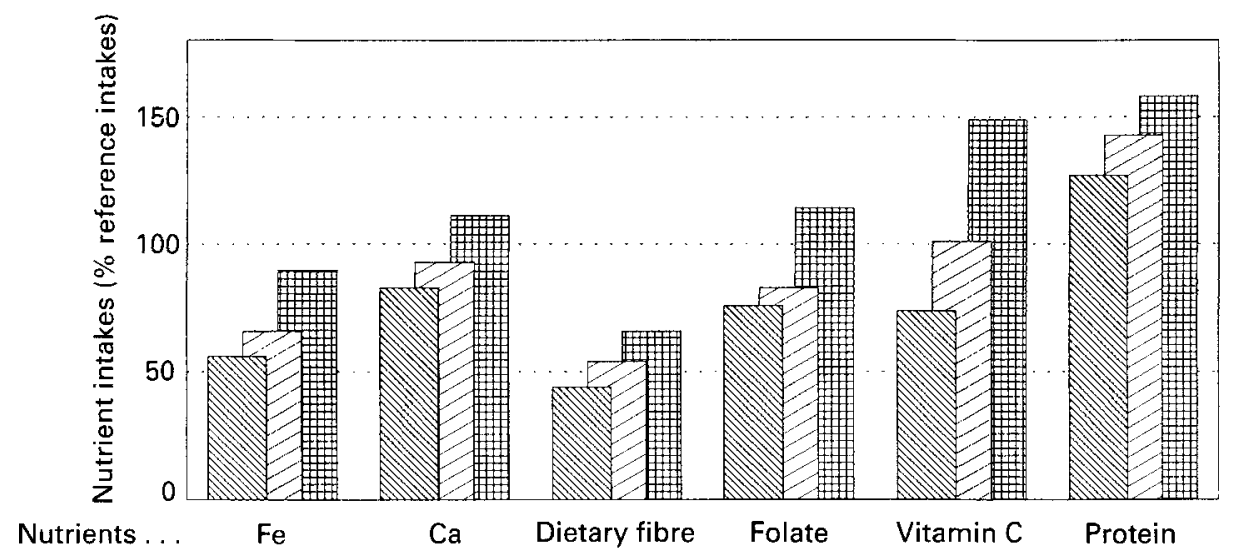

Fig. 1. London Lone-Parent Household Survey. Adequacy of lone-parents' nutrient intake 1992-3 from weighed food survey ( $n$ 118). (\$), Poverty index 2, long-term unemployed council tenants, no holiday and whose rent or fuel (and arrears) are automatically deducted from benefit, or paid via a key meter; (ש), poverty index 1, either unemployed council tenants or with rent and/or fuel deductions; ( category. All differences were significant $(P<0 \cdot 01)$. Nutrient intakes were related to current Department of Health (1991) dietary reference values which were chosen for each individual according to weight, age and activity level.

Table 3. London Lone-Parent Household Survey. Factors associated with higher total variety scores in lone parents' diets*

Most important: $\dagger$

Ethnicity (being black)

Looking for 'freshness' when buying food

Not being poor

Paying bills by direct debit

Also important: $\div$

Not choosing food just because your children will eat it

Shopping in supermarkets, markets and specialist shops as well as in discount stores

Not buying food just because it is 'cheap'

Looking for 'healthy' food when shopping

Not having a limited budget irreversibly committed to paying bills or households goods (auto-deduction from benefit)

\footnotetext{
* Factors are not listed in any particular order within the categories and factors which did not differentiate variety scores are not shown.

$\dagger$ Factors independently associated with high variety frequency scores.

$\ddagger$ Factors independently associated with high variety frequency scores within demographic, socio-economic, cultural and budgeting variables.
}

asked what qualities they looked for in the food they bought, and what their aims were in feeding their family, as a way into the discussion about food and health. These questions were open-ended; no prompt cards were used, and people could answer in any way they chose. Those who volunteered that they sought 'fresh' or 'healthy' food were found to have higher VFS and healthier dietary patterns than those who did not proffer such 
Table 4. London Lone-Parent Household Survey. Factors associated with higher fruit and vegetable variety scores in children's diets*

Most important: $\dagger$

Having a parent who looks for 'freshness' choosing food

Having a parent who aims at 'variety' in feeding the family

Also important: $\$$

Not coming from a poor household

Ethnicity, having black parents

Having an older parent

Having a parent who doesn't just look for food that is 'cheap'

Having a parent who doesn't pay for goods through a catalogue

Less important:\$

Where fruit and vegetables are bought

Having a parent with a job

Having a parent who receives Income Support

\footnotetext{
* Factors are not listed in any particular order within the categories and factors which did not differentiate variety scores are not shown.

$\uparrow$ Factors independently associated with high variety frequency scores.

\$Factors independently associated with high variety frequency scores within demographic, socio-economic, cultural and budgeting variables.

$\S$ Factors not independently associated with high variety scores but which showed some effect on their own.
}

aspirations. Even lone parents in the poorest categories of the material deprivation index but who said they looked for 'fresh' food in shopping had higher VFS and healthy diet indices than those who did not, although those who were not poor did better still.

\section{FURTHER ANALYSIS OF FOOD-CHOICE VARIABLES}

The strength of these associations, which were somewhat unexpected, prompted further lines of enquiry; responses to questions about dietary aspiration were analysed using factor and cluster analyses, to investigate patterns in the reponses, if any. Cluster analysis is a generic term describing classification techniques which look empirically for the presence of groups of cases or individuals where members of each group are as similar or like each other as possible in terms of some specified characteristics, and as unlike members of other groups. Cluster analysis does not require the investigator to specify in advance the basis of group membership, nor the number of groups and, therefore, can be used to search for natural groupings in a data set (Everitt, 1980; Aldenderfer \& Blashfield, 1984).

Binary variables were created from parents' answers to the dietary aspiration questions 'when you are buying food, what are you looking for?' and 'what are your aims in feeding your family?' (answers coded as 'other' and, therefore, not used in the first round of analysis were recorded by hand from the post-coding sheets). There were eleven food-choice variables and eight food-aims variables, with very few missing values. Cluster analyses were based first on the variables' similarity correlation matrices, using signed and absolute values of the correlations; and second on parents as cases, to see if groups of parents sharing similar response could be identified. Subsequent discriminant 
Table 5. London Lone-Parent Household Survey. Cluster analysis five group solution based on responses to questions of 'food choice' and 'food aims' combined

(Signed rather than absolute values of correlation coefficients were used; average linkage between groups method)

\author{
Best I can afford, learn to enjoy food, provide variety \\ Quality, freshness, value-for-money, provide kids a good diet, provide balanced diet, provide \\ healthy food, healthy food \\ Special offers, what I usually buy, what kids will eat, what I like to eat, satisfy family \\ Cheapness and/or price, not to be hungry \\ Future health and/or growth, what I fancy
}

analysis provided characteristics of the groups. Analyses were done using SPSS/PC $+4 \cdot 0$ (Norusis \& Statistical Package for Social Sciences Inc., 1990) which provides facilities for agglomerative hierarchical clustering, and methods for combining clusters were average linkage between groups and Ward's, based on squared Euclidian distances.

Table 5 shows the best solutions produced using the signed values of the correlation coefficients for all variables combined. The correlation coefficients in the matrices were not large, but several were significant at $P<0.01$ and $P<0.001$. Clustering variables of food choice and food aims separately gave similarly consistent patterning of responses. The groupings of variables supports the idea that people do have a consistent philosophy towards choosing food that combines immediate qualities, such as cost and quality from appearance, with more long-term aims, such as satisfying family desires or maintaining future physical well-being.

Clustering parents on the basis of their food-choice variables resolved essentially into five groups; key variables could be identified clearly for three using discriminant analysis; these are shown in Table 6. These group-membership identities were tested $v$. VFS and independent variables using ANOVA (regression approach), simple correlation and chi-squared tests of association. There were significant differences in VFS (adult and child total variety; adult and child fruit variety and vegetable variety were tested) across the cluster groups $(P<0 \cdot 0005)$. A consistent pattern was seen, those in the first cluster group (freshness/quality) were always much higher than any other group; the difference was probably the main contributor to the statistical significance.

The findings confirm that distinguishable approaches to food choice led to significantly different outcomes in terms of what foods people said they actually bought or ate, and how often. Testing the clusters against independent variables showed that cluster-group membership was not associated with income or occupational social class, but was associated with ethnicity and the material-deprivation index. Black parents were more likely to be in group one (freshness and/or quality) or groups two or three (cheapness and/or price and mixture of responses) than in groups four or five (I look for what I usually buy and/or what the kids will eat; $P=0.0008$ ) whose members were mostly white. Those in the worst category of the poverty index were more likely to be in group five (I buy what the kids will eat and/or what I like) and less likely to be in group one (freshness and/or quality) than parents who were not in either poverty category $(P=0.003)$. There was a weak association between smoking and group membership $(P=0.02)$; members of the first group were less likely to smoke than those in the second group. 
Table 6. London Lone-Parent Household Survey. Key variables associated with five clusters based on lone parents as cases, for 'food choice' variables*

\begin{tabular}{ccl}
\hline $\begin{array}{c}\text { Group } \\
\text { no. }\end{array}$ & $\begin{array}{c}\text { No. of } \\
\text { parents }\end{array}$ & \multicolumn{1}{c}{ Variable } \\
\hline 1 & 65 & $\begin{array}{c}\text { Freshness, quality, value for money, very negative on cheapness } \\
\text { and/or price } \\
\text { Cheapness and/or price } \\
\text { Cheapness and/or price, usually buy, what I like and/or what the } \\
\text { kids will eat } \\
3\end{array}$ \\
41 & 29 & What I usually buy \\
4 & 29 & What I like and/or what the kids will eat \\
\hline
\end{tabular}

* Discriminant analysis was used to assign key variables to groups. Three of the four discriminant functions retained large eigenvalues, had high canonical correlation coefficients and small Wilks' lamda; all were significant. Of all grouped cases $91 \%$ were correctly classified. Over $90 \%$ of groups 1,2 and 4 were correctly classified, 83 and $88 \%$ respectively were correctly classified for groups 3 and 5. Mapping confirmed that five groups could reasonably be distinguished, with more separation for groups 1,2 and 4 .

\section{CONCLUSIONS}

Lone parents who either shopped for 'fresh' food, by which they usually meant 'good quality' rather than not frozen or tinned, or said they wanted a healthy varied diet for their family, seemed to achieve better VFS and healthy diet indices for themselves and their children, than those who didn't mention these aims. There was no association between shopping patterns and the nutritional indicators except that those who used discount stores exclusively (who had the lowest incomes) had lower VFS and less healthy dietary patterns than those who either used discount stores in combination with markets, specialist shops and supermarkets, or did not use them at all. Those who used their children's taste as a guide in buying food, who were likely to be poorer, were more likely to have unhealthy patterns. Those who have little money for food cannot afford to be choosy or to experiment; they have no flexibility for meals to be rejected.

Black British and Afro-Caribbean households had better dietary variety and healthy dietary patterns than white, and to some extent, better micronutrient status. There has been little research on Afro-Caribbean diets in Britain; anecdotal evidence supports our finding that black parents always cooked from raw, fresh ingredients, and provided a highly varied diet for their families. Few other factors seemed to account for the differences in nutritional outcomes, which were not large, but were consistent.

There was no convincing evidence from the interviews that health or nutrition education campaigns had affected dietary aspirations; it was not obvious why some people held one set of attitudes and some another, 'looking for fresh' food rather than 'what the children will eat', finding time and money to shop around. What was clear was that many want quality in relation to food, even though their economic circumstances might be limited because they claim Income Support. We should not assume that poor people just look for cheap food, and that they do not have aspirations in common with those in the population who are not poor. One mother in the survey with two teenagers described the problems faced by many lone parents in her position (working voluntarily 
and claiming Income Support) of needing to 'fill people up in an interesting way' because 'children demand that, they demand to be fed'. But she was determined her children should enjoy food too, and eat as varied and nutritionally sound a diet as she could provide; "cooking is like a celebration for me . . . the central part of the home life is food'.

The authors would like to thank the lone parents who took part in the survey, and their families for their patient cooperation. The authors are also grateful to Peter England at the London School of Hygiene and Tropical Medicine, Alizon Draper at the World Cancer Research Fund, and Mark Myatt, for statistical advice. The Joseph Rowntree Foundation provided support for the lone parent nutrition survey, and Ministry of Agriculture, Fisheries and Food supported the secondary data analysis, but the authors alone are responsible for the findings and conclusions presented here.

\section{REFERENCES}

Aldenderfer, M. S. \& Blashfield, R. K. (1984). Cluster Analysis. Series: Quantitative Applications in the Social Sciences. London: Sage Publications.

Bradshaw, J. \& Millar, J. (1991). Lone Parent Families in the UK. Department of Social Security Research Report no. 6. London: H.M. Stationery Office.

Burghes, L. (1993). One-parent Families: Policy Options for the 1990's. York: The Joseph Rowntree Foundation.

Calvert, C., Rushton, C. \& Dowler, E. A. (1994). Dietary intakes of female lone parents in London: energy and micronutrients. Proceedings of the Nutrition Sociefy 53,97A.

Central Statistical Office (1994). Social Trends 24. London: H.M. Stationery Office.

Department of Health (1991). Dietary Reference Values for Food Energy and Nutrients for the United Kingdom. Report of the Panel on Dietary Reference Values of the Committee on Medical Aspects of Food Policy, Department of Health. Report on Health and Social Subjects no. 41. London: H.M. Stationery Office.

Department of Health (1994). Nutritional Aspects of Cardiovascular Disease. Report of the Cardiovascular Review Group of the Committee on Medical Aspects of Food Policy, Department of Health. Report on Health and Social Subjects no. 46. London: H.M. Stationery Office.

Department of Health and Social Security (1974). Report of the Committee on One Parent Families (Finer Report). London: H.M. Stationery Office.

Department of Social Security (1994). Income Support Statistics Annual Enquiry: May 1993. London: Department of Social Security.

Dobson, B., Beardsworth, A., Keil, T. \& Walker, R. (1994). Diet, Choice and Poverty: Social, Cultural and Nutritional Aspects of Food Consumption Among Low Income Families. London: Family Policy Studies Centre.

Dowler, E. \& Calvert, C. (1995). Nutrition and Diet in Lone-parent Households in London. London: Family Policy Studies Centre.

Dowler, E. \& Rushton, C. (1994). Diet and Poverty in the UK: Contemporary Research Methods and Current Experience: a Review. Department of Public Health and Policy Publication no. 11. London: London School of Hygiene and Tropical Medicine, University of London.

Dubos, R. (1984). The mirage of health. In Health and Disease: A Reader, pp. 4-9 [N. Black, D. Boswell, A. Gray, S. Murphy and J. Popay, editors]. Milton Keynes: Open University Press.

Everitt, B. (1980). Cluster Analysis. 2nd ed. London: Heinemann Educational Books.

McKay, S \& Marsh, A. (1994). Lone Parents and Work. Department of Social Security Research Report no. 25. London: H.M. Stationery Office.

Myatt, M. \& Dowler, E. (1995). Measuring Dietary Variety: Experience from the UK Lone Parent Nutrition Survey (In the Press).

Norusis, M. J. \& Statistical Package for Social Sciences Inc. (1990). SPSS/PC+ Statistics 4.0 for the IBM $P C / X T / A T$ and PS/2. Chicago, Ill.: SPSS Inc. 
Townsend, P., Corrigan, P. \& Kowarzik, U. (1987). Poverty and Labour in London. London: Low Pay Unit. Wheeler, E., Stewart, J. \& Schofield, C. (1989). Dietary variety during and after pregnancy in Scotland and England. Journal of Human Nutrition and Dietetics 2, 7-18.

Williams, C. (1994). Fruit and veg: go for five! Which? Way to Health June, 96-97.

Williams, C. \& Dowler, E. (1994). Identifying Successful Projects on Diet and Low Income: a Review of the Issues. Working Paper no. 1, Low Income Project Team; Nutrition Task Force. London: Department of Health.

Yarnell, J. W. G., Fehily, A. M., Milbank, J. E., Sweetnam, P. M. \& Walker, C. L. (1983). A short dietary questionnaire for use in an epidemiological survey: comparison with weighed dietary records. Human Nutrition: Applied Nutrition 37A, 103-112. 